\title{
A Ética da Tolerância como possibilidade de abertura hermenêutica do Direito: uma análise sobre a Jurisdição Constitucional Brasileira
}

\author{
The Ethics of tolerance as a possibility for an aperture of Legal \\ Hermeneutics: an analysis on the Brazilian Constitutional \\ Jurisdiction
}

Pedro Henrique Nascimento Zanon ${ }^{1}$

João Maurício Adeodato ${ }^{2}$

\section{RESUMO}

Este artigo objetiva analisar a ética da tolerância como possibilidade para uma abertura hermenêutica do direito no Brasil, tendo a jurisdição constitucional da Suprema Corte como pano de fundo. A problemática que orienta a pesquisa é assim definida: qual o papel da ética da tolerância na construção de uma jurisdição constitucional de um direito dogmaticamente organizado no Brasil? Conclui-se que a jurisdição constitucional brasileira não possui matrizes teóricas que a fundamentem. A atuação da Suprema Corte resulta assim numa construção caótica de discursos direcionados ao convencimento de um auditório acrítico.

\section{PALAVRAS-CHAVE:}

Ética da tolerância; Hermenêutica jurídica; Jurisdição constitucional; Retórica analítica; Abertura hermenêutica do direito.

\begin{abstract}
This paper aims to analyze the ethics of tolerance as a possibility for an interpretive aperture of legal hermeneutics in Brazil, having the constitutional jurisdiction of the Supreme Court as background. The problem that guides this research is thus defined: what is the role of the ethics of tolerance in the construction of a constitutional jurisdiction of a dogmatically organized law in Brazil? It is concluded that the Brazilian constitutional jurisdiction does not have theoretical matrices to justify its decisions. The performance of the Supreme Court then results in a chaotic construction of legal discourses directed to the conviction of an uncritical audience.
\end{abstract}

\section{KEYWORDS:}

Ethics of tolerance; Legal hermeneutics; Constitutional Jurisdiction, Analytical rhetoric; Aperture of legal hermeneutics.

\footnotetext{
${ }^{1}$ Doutor e Mestre em Direito (FDV). Professor da Faculdade de Direito da Universidade do Estado de Minas Gerais (UEMG). Universidade do Estado de Minas Gerais.

2 Livre-docente, Doutor e Mestre em Direito (USP). Professor Permanente da Faculdade de Direito (FDV). Pesquisador I-A (CNPq). Faculdade de Direito de Vitória.
} 


\section{INTRODUÇÃO}

No final do século XVI e início do XVII, Francis Bacon critica a educação de sua época por ser demasiadamente voltada para a retórica e por dar pouca importância, em sua concepção, às verdadeiras ciências (ADEODATO, 2011, p. 335). Para ele, as verdadeiras ciências seriam aquelas de metodologia indutiva e cunhadas no positivismo em início de ascensão na época. Hoje a situação é totalmente diversa: o atual paradigma da sociedade privilegia as ciências ditas ontológicas por conta dos surgimentos e desenvolvimento do positivismo epistemológico da escola realista e empirista (GERMANO, 2011, p. 51). Boaventura de Souza Santos destaca que o positivismo lógico unifica a ciência pelo método de explicação hipotético-dedutivo e na contribuição fundamental que a matemática possui para estabelecer uma ciência de rigor (SANTOS, 2003, p. 52).

No direito não é tão diferente. A jurisdição constitucional é pressionada pelo sucesso dos positivistas a adotar métodos racionais em suas decisões, os quais são muito parecidos com os aplicados nas ciências exatas. Todavia, o que se verifica na prática jurídica é que esses métodos são utilizados apenas como figuras retóricas para convencer o público de que se está adotando uma postura científica nas decisões. Essa afirmação é fruto das pesquisas de Theodor Viehweg (1979) e Ottmar Balweg (2011), que compõem a base teórica deste trabalho.

A atuação retórica pode ser percebida na jurisdição brasileira. Por exemplo, os ministros da Suprema Corte não concordam quanto ao conteúdo de significado de terminologias jurídicas como "dignidade da pessoa humana" ou "devido processo legal" e se utilizam-de artifícios retóricos para convencer o público de seus julgamentos, ao mesmo tempo em que escondem as premissas de pensamento em que estão apoiados.

Como então equilibrar essa profusão de interpretações no direito? Diante desse mar de interpretações possíveis, a ética da tolerância propõe que a legitimidade de um julgamento seja postulada na medida em que o julgador revele as premissas de sua decisão e pelo reconhecimento de que não é possível uma interpretação ser absoluta em detrimento das demais. Formula-se, portanto, a seguinte pergunta a ser enfrentada neste trabalho: qual o papel da ética 
da tolerância na construção de uma jurisdição constitucional de um direito dogmaticamente organizado no Brasil?

\section{A ABERTURA HERMENÊUTICA DO DIREITO É UMA CONSEQUENCIA DOS DIVERSOS PARADIGMAS DA FILOSOFIA METAFÍSICA COMO MÉTODOS INTERPRETATIVOS DE NORMAS JURÍDICAS}

No curso da história, podem ser identificados várias modelos de constituições diferentes com bases ideológicas e filosóficas distintas e que variam, por vezes, dentro do próprio Estado. Até mesmo nos EUA, onde a Constituição mantém o mesmo texto, o contexto a ela integrado já foi interpretado de diversas formas, como se várias constituições distintas fossem. O início do século XXI no Brasil transparece uma crise de legitimidade da Constituição, em que se propõe uma reforma do texto constitucional como via para uma reforma política. Quando se limita a interpretação à ideia de texto está-se partindo de uma concepção simplista que não irá resolver as mazelas constitucionais. Se a Constituição pode ser interpretada de inúmeras maneiras, seria válida a pretensão de dizer que uma dessas interpretações é a correta, em detrimento das demais? O perigo de reconhecermos que o texto não tem um sentido inerente, e que seu conteúdo é uma construção, é cairmos no decisionismo, ou seja, já que tudo é construção, qualquer uma é válida desde que realizada pela autoridade competente. Por outro lado, assumir que o texto de uma norma jurídica possui uma essência, como proposto pela Escola da Exegese francesa, seria compreender que o texto jurídico possui pretensão de cientificidade como verdade.

A tese que defende verdade e correção no direito pretende dizer que uma norma ou interpretação do direito positivo pode se afirmar como correta em detrimento de outras interpretações possíveis. O outro polo da discussão irá argumentar que o direito não tem uma pretensão de cientificidade nesse sentido, a exemplo de como descobrir a solução de uma equação.

O relato da cientificidade do direito, muito acompanhado pelos seguidores de Savigny, deságua, quase sempre, no argumento de que a decisão jurídica é fruto da aplicação do método 
de dedução lógica (LARENZ, 1997, p. 24). Em contrapartida, os retóricos analíticos tendem a argumentar que a decisão judicial é formada por uma retórica estratégica, ou seja, o conhecimento jurídico não é científico, pois a decisão judicial é um discurso criativo dirigido a um público determinado (SCHLIEFFEN, 2006, p. 60).

Esses discursos criativos, por sua vez, são concebidos a partir de determinadas premissas. As interpretações jurídicas também partem de diversos paradigmas filosóficos, da metafísica clássica à metafisica moderna e à pós-metafísica. As condições de acesso ao objeto investigado irão refletir nas interpretações que podem ser consideradas como válidas ou inválidas. Essas questões envolvem uma discussão da relação entre o sujeito cognoscente e o objeto cognoscível.

\subsection{A metafísica clássica na hermenêutica jurídica.}

A metafísica clássica tem origem em Sócrates, Platão e Aristóteles, e pode ser conectada a concepções do direito, embora não mais adequadas atualmente ao paradigma do Estado Democrático moderno. Os termos utilizados por Aristóteles para designar a metafísica são filosofia primeira ou ontologia, pois trata das questões essenciais que vão além do mundo físico. Há uma hierarquia entre as reflexões filosóficas, físicas e matemáticas. A filosofia primeira, ou metafísica, era considerada a mais importante pela própria concepção de acesso do homem ao conhecimento. Na metafísica de Platão, a realidade é descoberta pela reflexão mental; as teses gerais, como o conhecimento de números ou fórmulas matemáticas, não se curvam aos dados da experiência empírica, que são considerados um desdobramento inferior do conhecimento primeiro (XAVIER, 2015, p. 122).

No paradigma da metafísica clássica, a relação entre sujeito e objeto é desequilibrada, porque há uma forte ênfase no objeto cognoscível e não no sujeito cognoscente. Algumas questões que são discutidas pela metafísica clássica podem ser assim resumidas: há diferença entre mente e matéria? Qual a essência das coisas? Existem outros mundos além do mundo material? Existem coisas absolutamente imutáveis? Platão, ao narrar um diálogo entre Sócrates e Glauco, no Livro VII de A República, ilustra o acesso do homem ao conhecimento das coisas 
por meio da alegoria da caverna. A premissa da alegoria da caverna é a existência de duas realidades. A realidade de indivíduos que habitam o subterrâneo é assim resumida:

\begin{abstract}
esses homens estão aí desde a infância, de pernas e pescoço acorrentadas, de modo que não podem mexer-se nem ver senão o que está diante deles, pois as correntes os impedem de voltar a cabeça; a luz chega-lhes de uma fogueira acesa numa colina que se ergue por detrás deles; entre o fogo e os prisioneiros passa uma estrada ascendente. Imagina que ao longo dessa estrada está construído um pequeno muro, semelhante às divisórias que os apresentadores de títeres armam diante de si e por cima das quais exibem as suas maravilhas (PLATÃO, 1996, p. 317)
\end{abstract}

Ao longo dessa estrada ascendente, indivíduos libertos caminham e por vezes lidam com objetos de toda espécie. Para os aprisionados, as sombras desses objetos projetadas pelo fogo no alto da colina representam o mundo, mas não passam de ilusões para os indivíduos libertos. Aqueles que vivem aprisionados na caverna acabam por criar um ambiente social entre eles. Um dos aprisionados consegue se desprender da caverna e se deparar com o mundo real. Todavia, aquilo que é visto no mundo dos libertos não faz sentido no mundo dos aprisionados, por contrariar o que foi experimentado na caverna. Ao retornar para o convívio na caverna e explicar a realidade do mundo, os libertos são condenados como loucos pelos aprisionados, por não compartilhar dos mesmos julgamentos. O conflito se instaura por divergência sobre o mundo das aparências, vez que o mundo real não aparece aos sentidos. Em sentido contrário, afirma Hannah Arendt (2010, p. 61): "Para nós, a aparência - aquilo que é visto e ouvido pelos outros e por nós mesmos, constitui a realidade". Nesse ponto, há ainda uma distinção entre aparência (appearance) e aparência ilusória (semblance):

Esta última, embora ilusória, pode ser autêntica, se for comum a muitos, como a impressão de que o sol gira em torno da Terra, e inautêntica, que é o caso de miragens, por exemplo; a possibilidade de erro está sempre presente no mundo das aparências e o erro é um fenômeno correlato a toda aparência ilusória, ou seja, a ilusão é natural na medida em que os órgãos de percepção e os pontos de vista admitem variações. (ADEODATO, 2016, p. 237)

O que torna a comunicação entre os indivíduos possível é a suposta objetividade do mundo compartilhado, seja no mundo dos libertos, seja no mundo dos aprisionados. Acostumado com a claridade, aquele que se libertou tem dificuldade em enxergar na escuridão da caverna e não mais reconhece as figuras mais básicas vivenciadas pelos aprisionados. Ao relatar a alegoria da caverna, Platão pretende fazer uma homenagem ao seu grande mestre Sócrates, que havia sido morto em razão das suas concepções de realidade. Os dois cenários apresentados representam o plano do mundo (aquilo observado no interior da caverna) e o plano das essências (aquilo observado do lado de fora da caverna). A essência do cavalo, por exemplo, 
representa uma imagem idealizada, dentre tantos outras que existem na realidade (cavalo com diferentes portes, cores, pelugem etc.).

Esta dupla percepção da realidade é posta por Platão como o mundo sensível, marcado por percepções ilusórias com caráter mutável, e o mundo das ideias. Este último, apesar de trazer elementos da realidade pela possibilidade de atingi-los de forma concreta e palpável, induz à afirmação de que todo objeto apenas é conhecido no plano das ideias, ou seja, não nos permite dizer que estes objetos possam ser conhecidos empiricamente.

Essa capacidade não implica dizer que, dentre os objetos de mesma espécie, seja possível distinguir todos os elementos que lhe são característicos. Todo objeto possui elementos que o individualizam diante dos demais, influenciados por diversos fatores, dentre eles as circunstâncias em que se encontram, o momento, o local, dentre outros que lhe proporcionaram características próprias. Portanto, não existe nenhum floco de neve igual ao outro e nenhum objeto é igual ao outro, da mesma forma que nenhuma experiência é igual a outra. Todos os objetos são únicos e todas as experiências são irrepetíveis.

Semelhante ao pensamento de que as coisas são apenas conhecidas no plano das ideias, a teoria do conhecimento de Immanuel Kant se conecta com a de Platão em relação à importância do conhecimento a priori da experiência. $\mathrm{O}$ fator que distingue as teorias é que, para Platão, tanto o conteúdo quanto as formas seriam a priori, motivo pelo qual descarta o empirismo e destaca o mundo das ideias. Já Kant dá ênfase a forma e matéria-e em sua teoria há traços tanto do racionalismo quanto do empirismo.

Que todo o nosso conhecimento começa com a experiência, não há dúvida alguma, pois, do contrário, por meio do que a faculdade de conhecimento deveria ser despertada para o exercício senão através de objetos que tocam nossos sentidos e em parte produzem por si próprios representações, em parte põem em movimento a atividade do nosso entendimento para compará-las, conectá-las ou separá-las e, desse modo, assimilar a matéria bruta das impressões sensíveis a um conhecimento dos objetos que se chama experiência? Segundo o tempo, portanto, nenhum conhecimento em nós precede a experiência, e todo ele começa com ela. Mas embora todo o nosso conhecimento comece com a experiência, nem por isso todo ele se origina justamente da experiência. Pois poderia bem acontecer que mesmo o nosso conhecimento de experiência seja um composto daquilo que recebemos por impressões e daquilo que a nossa própria faculdade de conhecimento (apenas provocada por impressões sensíveis) fornece de si mesma, cujo aditamento não distinguimos daquela matéria-prima antes que um longo exercício nos tenha tornado atentos a ele e nos tenha tornado aptos à sua abstração. (KANT, 1987, p. 1.) 
Na metafísica clássica, toda reflexão científica deveria ser feita com base na reflexão e no raciocínio, enquanto os dados empíricos seriam completamente desprezados. As tarefas assumidas pela metafísica clássica, em contraponto com a doutrina do direito até mesmo dos dias atuais, é identificar categorias gerais, conceitos acerca da identidade e substância das coisas. Essa tarefa consiste em estabelecer relações entre essas categorias que irão classificar os entes, que são os objetos cognoscíveis, quase que arqueologicamente, pela reflexão mental. Nesse contexto, a palavra da linguagem é um mero instrumento de transmissão das ideias, é possível pensar na metafísica sem a linguagem.

\subsection{A metafísica moderna e a hermenêutica jurídica.}

A transição da Idade Média para a Idade Moderna marcou uma ruptura de paradigma na filosofia acerca do acesso do homem ao conhecimento dos objetos. Essa quebra marca a transição entre a metafísica clássica e a metafísica moderna. A metafísica moderna expressa-se pelo racionalismo do iluminismo (Aufklärung). Mas tanto no paradigma da metafísica clássica quanto no da metafísica moderna, o objeto que se pretende conhecer tem uma essência que pode ser desvelada. Na metafísica moderna, quando o cientista erra é porque não aplicou o método corretamente. Assim, o objetivo central da ciência é revelar a verdade ou a resposta sobre o objeto que se quer conhecer.

O racionalismo começou a investir nos objetos físicos e empíricos que se pretendiam conhecer, somente a investigação por meio das ideias era insuficiente. Nas duas metafísicas, acreditava-se que se poderia descobrir o objeto de uma maneira definitiva e absolutamente atemporal, ou seja, haveria uma verdade a ser revelada. Por isso, reflexivamente, a hermenêutica jurídica da Escola da Exegese e da Jurisprudência dos Conceitos, por exemplo, considera que há uma essência hermenêutica objetiva na lei, a ser descoberta pelo intérprete.

\subsection{A pós-metafísica moderna e a hermenêutica jurídica.}

O caráter científico é conferido pela neutralidade, mas o investigador possui compreensões prévias, crenças e tradições que devem ser extirpadas do processo científico. O 
método científico serve para excluir as crenças e permitir uma análise supostamente neutra acerca do objeto. Lenio Streck (2008, p. 260) denomina de paradigma da filosofia da consciência essa pretensa neutralidade do caráter científico, ou seja, a reflexão mental começa na consciência, mas as precompreensões devem ser extirpadas pelo método científico. Ao trazer essas ideias para o direito, podemos associá-las à Escola da Exegese, que pretende criar um método capaz de revelar aquilo que seria a essência da norma interpretada e tirar do intérprete toda sua carga subjetiva.

A obra $O$ discurso do método, de René Descartes (2011), é uma marca desse racionalismo. Antes de publicar esta obra, Descartes realizou uma pesquisa sobre a refração da luz e ficou amedrontado por eventual condenação por heresia pelo Santo Ofício devido aos resultados de seu trabalho, ao ter como parâmetro a condenação que Galileu sofreu. Galileu era apadrinhado do Papa de sua época, mas por insistir que a terra girava em torno do sol foi condenado, todavia sua pena foi mais branda. Descartes, como não tinha a influência de Galileu, ficou receoso em afrontar as compreensões do Santo Ofício e ser condenado à pena de morte.

Descartes então escreve $O$ discurso do método para explicar que o cientista não pode ser condenado pelos resultados do trabalho, trata-se apenas de um mensageiro do método científico. O cientista não constrói ou revela nada, e por isso ele não pode ser responsabilizado pelas descobertas, é o método que revela os resultados, assegurando que se coloque de lado toda a compreensão do intérprete, que apenas descreve aquilo que é o objeto cognoscível. Por este pensamento, qualquer pessoa que aplique corretamente o método chegará à mesma conclusão. Essa publicação de Descartes pretendeu viabilizar a divulgação de sua pesquisa sobre a refração da luz, mas tornou-se a maior de suas obras.

Descartes diz que o preconceito ofusca a compreensão ontológica do objeto, que se deve estimular o método dedutivo e que a aplicação da dedução é capaz de produzir o conhecimento correto, atemporal e definitivo. Posteriormente, Gadamer defenderá a hipótese de que o método não pode trazer a verdade nas ciências do espírito e coloca a seguinte indagação: como é possível apreciar uma obra de arte sem uma precompreensão que condiciona essa leitura? A hipótese é de que isso não é possível, tanto que, se existem críticos de arte, é porque possuem precompreensões que os incautos não têm. A hermenêutica de Gadamer reabilita o conceito de preconceito ao dizer ser ele necessário; então, cabe à ciência discutir os preconceitos no sentido 
de pressuposição ou preconcepção. O importante é desvelar quais são as precompreensões que estão por trás de qualquer afirmação e verificar se são válidas ou não.

Este é o ponto de partida do problema hermenêutico. Por isso havíamos examinado o descrédito do conceito do preconceito no Aufklärung. O que, sob a ideia de uma autoconstrução absoluta da razão, se apresenta como um preconceito limitador, é parte integrante, na verdade, da própria realidade histórica. (GADAMER, 1998, p. 416)

Gadamer pretende dizer que a pretensão de depurar os preconceitos por meio do método científico se apresenta sob a ideia de autoconstrução absoluta da razão. Todavia, a própria escolha de um método parte de um preconceito, de uma preconcepção. Essa pretensão, portanto, já é um preconceito, haja vista que a escolha do método é conduzida por algo que já é posto. A preconcepção ou preconceito é parte da realidade histórica.

Se se quer fazer justiça ao modo de ser finito e histórico do homem [esta era a
compreensão de Heidegger, ao orientar Gadamer], é necessário levar a cabo uma
drástica reabilitação do conceito do preconceito e reconhecer que existem
preconceitos legítimos. (GADAMER, 1998, p. 417)

A ideia de preconceito ou preconcepção é aquilo que permite ao homem não ter que reinventar a roda a cada geração. Ao realizar uma pesquisa, o cientista não refaz todo o processo científico, ao invés disso, ele adota premissas. Esse é o marco teórico de qualquer tese. Outra ideia fundamental na obra de Gadamer é a noção de círculo hermenêutico, que é condição de possibilidade na produção do conhecimento científico e de interpretação no direito.

A ideia de círculo hermenêutico é colocar em cheque a separação entre sujeito e objeto. Se o sujeito cognoscente tem que partir de preconcepções para construir o sentido do objeto a ser analisado, significa que um pouco desse objeto é projeção das precompreensões que o sujeito carrega. Por exemplo, um índio (sujeito) ao ver uma caravela (objeto) pela primeira vez é diferente de um navegador (sujeito) que enxerga a mesma caravela. O objeto que se enxerga é fruto da preconcepção que se projeta. A ideia de tempo que compartilhávamos antes da teoria de Einstein é diferente da ideia que os físicos compartilham hoje, porque eles têm bagagens que projetam quando discutem um problema da passagem do tempo. Isso constitui a maneira como enxergamos o mundo e aquilo a que chamamos de realidade, que é uma construção a partir de precomprensões.

O círculo hermenêutico dirá que o conhecimento do objeto se dá a partir de precompreensões, mas a preconcepção ou precompreensão também é enriquecida e 
transformada por meio do contato com o objeto. Por exemplo, ao lermos um livro, para que o título faça sentido é necessário projetá-lo no todo no qual o livro é escrito. Por exemplo, o título da obra $O$ império do Direito pode ter projeções distintas para cada indivíduo, como para um jovem que acabou de ler $O$ senhor dos anéis ou para um sociólogo. Ao ter a precompreensão de que se trata de uma obra de teoria do direito, a projeção do título é alterada. Nesse sentido, o círculo hermenêutico é a dialética na relação sujeito e objeto.

O direito não deve cair em decisionismo porque embora possa ser interpretado de múltiplas formas, ele também constitui algo objetivo. Gadamer reforça a crítica na crença da neutralidade do método científico e denomina esse movimento de virada hermenêutica da filosofia contemporânea. Hermenêutica não pensada como método de revelar sentidos, mas como ato de pensar e desvelar preconceitos, demonstrando quais são legítimos e quais devem ser refutados.

\section{A RETÓRICA ANALÍTICA E O CONTROLE DA LINGUAGEM NO DIREITO DENUNCIAM UMA ORGANIZAÇÃO RETÓRICA DA JURISPRUDÊNCIA CONSTITUCIONAL E UMA ERÍSTICA DO DISCURSO JURÍDICO}

\subsection{Sobre a retórica analítica: as decisões jurídicas são produto de um método lógico ou retórico?}

A retórica surge de forma propriamente jurídica, antes mesmo da famosa publicação de Aristóteles (2013) sobre o tema. Os primeiros relatos remontam à Grécia Antiga do século V a.c., na cidade de Siracusa ${ }^{3}$. Córax de Siracusa, um retórico da época, elaborou um sistema dogmático de técnicas de influência pela argumentação. Essa obra, todavia, apenas é conhecida pela doxografia (ADEODATO, 2011, p. 251). Posteriormente, os sofistas se utilizam da retórica em suas técnicas de ensino com enfoque na oratória e na capacidade de argumentação. Eles

\footnotetext{
${ }^{3}$ Após as tiranias de Gelon e seu sucessor, Hieron I, as terras dos indivíduos que haviam sido então confiscadas foram redistribuídas aos antigos proprietários. Todavia, se passaram muitos anos desde as primeiras expropriações e o único meio de adquirir a propriedade perdida era pela argumentação. Ocorre que nem todos tinham o dom de argumentar propriamente em defesa de seus direitos e contratavam aqueles que melhor detinham da retórica para relatar seu direito de propriedade (ADEODATO, 2011, p. 250).
} 
eram simultaneamente professores e especialistas em direito, se profissionalizavam em preparar os cidadãos que precisavam se apresentar em juízo na época.

era necessário conceber e estruturar o discurso, encontrar argumentos, memorizar a exposição e treinar a apresentação. Dado que esse treinamento retórico foi associado ao sucesso do procedimento, aos honorários e ao próprio valor de mercado, havia para esses primeiros professores de retórica certamente um maior estímulo para que aumentassem seus conhecimentos na arte da linguagem" (SCHLIEFFEN, 2006, p. 44).

Dispõe-se, então, da retórica enquanto método de abordagem para análise dos paradigmas do direito. Por esse caminho, a retórica pode ser entendida em três acepções principais: retórica material; retórica estratégica ou prática; e retórica analítica ${ }^{4}$. O viés desta pesquisa recai sobre a retórica analítica.

Charles William Morris defende que a retórica é uma precursora da semiótica; já para Ottmar Balweg, a semiótica é uma forma restrita da retórica (BALLWEG, 1987, p. 28). Ballweg propõe a formulação da retórica enquanto descrição (analítica) de como a linguagem humana é estrategicamente utilizada para obter o convencimento do público. Por essa concepção, a retórica analítica não se reduz a um método ou metodologia, mas constitui uma metódica da linguagem.

A metódica jurídica consiste numa teoria sobre a relação entre a teoria da prática (a metodologia, a doutrina dogmática, no caso do direito) e essa mesma prática (conjunto de métodos); procura uma metateoria, que veja o caso concreto em relação com as metodologias que o procuram conformar. (ADEODATO, 2010, p. 75-76).

A retórica analítica é projetada por Ballweg no direito para demonstrar que a prática jurídica e o estudo dogmático do direito são formulados por posições de retóricas estratégicas e não a partir de metodologias rigorosas ou por padrões lógicos.

Katharina Sobota $(1992)^{5}$ propõe um novo método na ciência do direito: a sismografia retórica. Em seu trabalho, a autora analisa as figuras retóricas ${ }^{6}$ utilizadas em julgamentos do Tribunal Constitucional Alemão. A conclusão é de que o tribunal constitucional emprega, em larga escala, figuras retóricas, sobretudo em partes das decisões consideradas mais importantes pela autora, como meio central de persuasão, muitos mais do que os textos legais alegados. $\mathrm{O}$ discurso do direito e as decisões jurídicas são, portanto, formulações de uma retórica estratégica

\footnotetext{
${ }^{4}$ Detalhes quanto a cada uma dessas acepções é detalhada por João Maurício Adeodato (2010).

${ }^{5} \mathrm{Na}$ época da publicação a autora se chamava Katarina Sobota, hoje Katharina von Schlieffen.

${ }^{6} \mathrm{Na}$ acepção da autora, figuras retóricas são estratégias linguísticas de convencimento como metáforas e ironias.
} 
que tem o objetivo de conquistar o convencimento do público. O sismógrafo retórico também revela que há uma tendência de os juristas ocultarem as premissas de pensamento em que se apoiam.

\subsection{A organização tópica da jurisprudência constitucional brasileira.}

Quando se trata de discurso constitucional, parte-se aqui da Teoria dos Sistemas Sociais de Niklas Luhman (1998) no sentido de que a norma constitucional seria o fruto do acoplamento estrutural entre os sistemas político e jurídico. No mesmo sentido, Celso Campilongo (1998, p. 58) afirma que, por ter teor político, a Constituição sofrerá interpretações diferenciadas e por uma metodologia própria. A norma jurídica constitucional, assim, é muito mais do que o texto: é o contexto.

O Estado Democrático de Direito no Brasil é uma consequência do contexto do constitucionalismo pós 1945, forjado na Europa por intermédio de teorias de direitos fundamentais que adentram o debate brasileiro a partir da primeira década pós 1988. Há um leque de autores, não necessariamente juristas, que compõem esse cenário como Jürgen Habermans, Robert Alexy, Klaus Gunther, Gustavo Zagrebelsky, Ronald Dworkin, Hebert Hart, dentre outros. Autores que trazem reflexões acerca de temas como democracia, ciência política e teoria do direito sob uma influência muito grande do campo filosófico e de sua atuação crítica sobre o direito e, com maior ênfase, o direito constitucional. No Brasil, há uma importação das teses desses autores europeus, porém quase sempre de forma desconexa com a realidade brasileira. De toda forma, aqueles que se apegavam às fórmulas hermenêuticas cristalizadas surpreendidos pelos novos métodos de interpretação da Constituição.

\footnotetext{
O problema da jurisdição constitucional brasileira, nesses tempos de transição, parece ser: o judiciário nem vê o texto ontologicamente, como um ícone do objeto, e o vincula a uma interpretação pretensamente fixa, como na exegese francesa da transição do século XVIII para o XIX, nem o concretiza por via de um projeto e de procedimentos hermenêuticos específicos. Tem os defeitos da reificação racionalista e os do casuísmo irracionalista: concepção reificadora, trato casuístico, uma esdrúxula incompatibilidade estratégica. Essa jurisprudência vem constituindo a parte mais significativa da retórica constitucional brasileira (ADEODATO, 2010, p. 211).
}

Ao observar os julgados do STF, cada ministro possui sua peculiar fundamentação na tomada de uma decisão e o colegiado não apresenta uma maioria que vota sob um mesmo 
espeque de raciocínio. Do mesmo modo, cada voto proferido não traz uma declaração honesta do caminho de pensamento adotado, o que demonstra que nos submetemos à tutela de um direito dogmaticamente desorganizado ou de uma organização retórica estratégica erística da jurisprudência constitucional. Por exemplo, é comum no STF ver um voto proferido que declara utilizar a teoria da ponderação de Robert Alexy, mas de fato a emprega equivocadamente ao limitar-se à equiparação entre proporcionalidade e razoabilidade, ou, por vezes, não a utiliza (DA SILVA, 2011, p. 32).

\subsection{A linguagem erística do discurso jurídico e o abismo gnosiológico na fundamentação de decisões.}

Grande parte dos sistemas jurídicos constitucionais a partir dos séculos XVII e XVIII irá recorrer a textos, de forma que a questão de sua interpretação passa a ser central no Direito. O texto é apenas a ponta do iceberg normativo. Isso significa que a construção da norma requer algo que está além do visível, o texto normativo é apenas uma pequena parte do que constitui a norma.

\footnotetext{
Por outro lado, a normatividade, pertencente à norma segundo o entendimento veiculado pela tradição, não é produzida por esse mesmo texto. Muito pelo contrário, ela resulta dos dados extralingüísticos de tipo estatal-social: de um funcionamento efetivo, de um reconhecimento efetivo e de uma atualidade efetiva desse ordenamento constitucional para motivações empíricas na sua área; portanto, de dados que mesmo se quiséssemos nem poderiam ser fixados no texto da norma no sentido da garantia de sua pertinência. (MÜLLER, 2005, p. 45)
}

A parte submersa do iceberg normativo são as precompreensões. Gadamer caracteriza esse fenômeno como o horizonte histórico no qual cada ser humano invariavelmente está inserido. Entre o texto e o sentido atribuído ao texto colocam-se os operadores do direito diante de um labirinto de possibilidades. Trata-se do que Carvalho Netto (2004, p. 40) denomina de "mar revolto de norma", dizendo que, para o julgador, a partir de um texto normativo, existem diversas normas que podem resultar da interpretação.

A jurisdição constitucional brasileira, enquanto integrada a um Estado democrático, se submete a um "constrangimento" de fundamentar as decisões. Ocorre que a Suprema Corte não demonstra levar esse quesito muito a sério: "a estratégica política do judiciário tem sido casuística, na medida em que as fundamentações têm variado a ponto de ser difícil seguir um 
vetor qualquer de racionalidade para unificação de jurisprudência" (ADEODATO, 2010, p. 211).

Teorias como a ponderação de princípios de Robert Alexy, da única decisão correta como na Escola da Exegese ou o Código Prussiano de 1794, e a teoria da moldura, proposta por Hans Kelsen, são largamente empregadas na jurisdição constitucional brasileira, sem, todavia, seguir os ditames teóricos propostos em cada uma delas. A declaração dos julgadores de que a decisão proferida é fruto da aplicação de uma ponderação de princípios é apenas mais uma figura de retórica estratégica para convencer o público que espera uma decisão racionalizada por parâmetros. Percebe-se que quem exige a racionalização metodológica da decisão constitucional é o público que possui como paradigma de pensamento os métodos da metafísica moderna, expostos no tópico inaugural deste trabalho.

A Suprema Corte, ao se submeter a exigência de agir conforme os ditames da metafísica moderna, se apropria de teorias de decisão judicial e agrava ainda mais o abismo gnosiológico de suas fundamentações. O uso de teorias de decisão judicial, sem o compromisso rigoroso de sua aplicação, demonstra a postura retórica irracional da jurisdição constitucional brasileira. Mas então, como atribuir legitimidade racional às decisões constitucionais irracionais?

\section{A ÉTICA DA TOLERÂNCIA PERMITE REDUZIR O ABISMO DAS DECISÕES JURÍDICAS AO AGIR COMO EIXO DE POSSIBILIDADE DE UMA JURISDIÇÃO CONSTITUCIONAL BRASILEIRA AUTORREFERENTE E CONSTITUTIVA DA REALIDADE}

\subsection{O papel da linguagem na construção do conhecimento jurídico autorreferente e constitutivo da realidade.}

René Descartes inaugurou a filosofia moderna com sua ênfase sobre o método, trabalhando a ciência e a investigação filosófica como um processo individual, no qual era possível o pensar independente da linguagem. A linguagem era concebida na filosofia moderna 
como mera expressão do pensamento. No sistema aristotélico, a linguagem tampouco é o centro da investigação, mas apenas um instrumento na busca dos resultados ontológicos:

\begin{abstract}
cada uma das coisas ditas, por si, não se diz em afirmação nenhuma, mas a afirmação nasce com a combinação de umas com as outras. Pois toda afirmação parece ser verdadeira ou falsa, e das coisas que se dizem sem nenhuma combinação, nenhuma é nem verdadeira nem falsa, como homem, branco, corre, vence (ARISTÓTELES, 2013, p.5).
\end{abstract}

Qual seria então a conexão entre a essência das coisas e o nome que se dá para elas? Para Aristóteles (2013, p. 3) "nem a escrita é a mesma para todos, nem os sons pronunciados são os mesmos". O nome seria apenas um rótulo que não exerce influência na essência das coisas. Inaugurando a "virada linguística", Wittgenstein, ao escrever O Tratado Lógico Filosófico, percebeu que a linguagem não é apenas expressão do pensamento, mas o constitui, abandonando a tradição de que ele seria simplesmente intermediado pela linguagem. Assim como Gadamer, Wittgenstein trabalhava a ideia de que o homem é fruto do seu tempo e de sua história porque são compartilhadas determinadas preconcepções.

A linguagem tampouco é construída de maneira individual, ela é pluralisticamente constituída. Wittgenstein (1996, p. 165-170) argumenta sua tese sobre dois pilares: 1) a linguagem constitui o pensamento; 2) esse pensamento não ocorre de maneira isolada, visto que é mediado e constituído por uma linguagem produzida intersubjetivamente. Podemos exemplificar com determinados sentimentos como "dor de cotovelo" ou "peso na consciência", metáforas que passam a constituir parte do mundo em que vivem. À medida que os horizontes linguísticos se ampliam a compreensão de mundo muda.

Carvalho Netto (2001, p. 15) diz que "nós nos comunicamos porque não nos comunicamos", isso significa que tomamos como assentes, em silêncio, que certos signos linguísticos possuem determinado significado sobre o qual não se discute e só então nos comunicamos. Assim não fosse, estaríamos buscando os significados de todas as palavras a todo tempo e o diálogo jamais aconteceria. No direito, podemos enxergar esses signos nas expressões como "dignidade da pessoa humana", "devido processo legal" ou "segurança jurídica". Sob essas expressões há um silencio gnosiológico que se torna autorreferente e, ao mesmo tempo, constitutivo da realidade. Todavia, assim como qualquer outro signo linguístico, vago e impreciso, essas terminologias jurídicas também podem ser interpretadas de formas 
diferentes por um ou outro jurista, conforme suas compreensões ou precompreensões. A profusão de interpretações é o que definimos como a abertura hermenêutica do direito.

\subsection{A ética da tolerância como eixo condutor na abertura hermenêutica do direito.}

Em setembro de 1994, um grupo de intelectuais das ciências humanas se reuniu na Universidade Federal do Rio de Janeiro para o Encontro pela Tolerância na América Latina e Caribe, para discutir uma concepção de tolerância a partir do cenário cultural dos povos latinoamericanos e caribenhos. Os debates foram gravados em vídeo e atualmente se encontram no Observatório de Educação em Direitos Humanos da Universidade Estadual Paulista Júlio de Mesquita Filho, campus de Bauru. O Encontro fez parte de um conjunto de sete conferências com o propósito de debater a formulação da Declaração de Princípios sobre a Tolerância de 1995. As conferências ocorreram nas cidades de Rio de Janeiro (Brasil), Seul (Coreia do Sul), Sienna (Itália), Cartago (Tunísia), Nova Délhi (Índia), Moscou (Rússia) e Istambul (Turquia).

As concepções apresentadas pelos intelectuais latino-americanos mostram influência do pensamento de Herbert Marcuse no artigo intitulado Repressive Tolerance, um capítulo da obra coletiva A critique of pure tolerance (1965). Marcuse é influenciado pela filosofia hegeliana e apresenta uma concepção de tolerância vinculada a posicionamentos políticos libertadores e com pretensões não hegemônicas. Sistemas políticos totalitários e com ideais desumanizadores não devem ser tolerados, ou seja, concepções como a base do chauvinismo francês, do paneslavismo, do pangermanismo, do nazismo, dentre outros fascismos, não devem ser toleradas, mas reprimidas em sua gênese. $O$ senso de tolerância se destina a posições libertadoras com reconhecimento da pluralidade de culturas entre os povos.

A realização do objetivo da tolerância exigiria intolerância para com as orientações políticas, atitudes e opiniões dominantes, e a extensão da tolerância perante as orientações políticas, as atitudes e opiniões colocadas fora da lei ou suprimidas. (MARCUSE, 1965, p. 81)

As concepções dos intelectuais na conferência do Rio de Janeiro seguiram o pensamento de Herbert Marcuse. Paulo Freire foi um representante do Brasil na conferência. Em seu discurso na abertura do evento enfatizou a tolerância como uma virtude e argumentou sobre seus limites: 
$\mathrm{O}$ ato de tolerar implica no clima de estabelecimento de limites, de princípios a serem respeitados. Por isso a tolerância não é a conivência com o intolerável. Sob o regime autoritário, em que a autoridade se exacerba ou sob regime licencioso, em que a liberdade não se limita, dificilmente aprendemos a tolerância (FREIRE, 1993, p. 4-5).

Com uma percepção equivalente, temos o posicionamento do peruano Juan Rivera Palomino, quando define que tolerância apenas pode ser compreendida em contextos democráticos, com valores de respeito e reconhecimento de direitos universais do homem. Palomino faz uma forte crítica à importação de filosofias eurocêntricas de desenvolvimento que suprimiram a filosofia andina e qualquer outra forma de pensamento que não fosse articulada com a razão instrumental. A colonização cultural europeia na América Latina é tida como totalizadora e seu objetivo é alcançar a homogenização, a estandartização de ideias, os estilos de vida, as crenças e os padrões de comportamento. Nesse sentido, a construção de um discurso de tolerância na América Latina tem a necessidade primeira de se libertar da concepção neoliberal e compreender outros modelos de política e sociedade.

Quanto ao direito, e especificamente à jurisdição constitucional, a ética da tolerância rejeita pretensões hermenêuticas dominadoras. Tolerância, portanto, não se confunde com pusilanimidade de aceitar qualquer ato, muito menos como postura de bonomia absoluta. Pela ética da tolerância, o primeiro quesito para um discurso jurídico ser legítimo é o afastamento de pretensões de impor aos demais posições alheias. Nessa trilha, o argumento que postula que decisão justa é apenas aquela proferida a partir de determinada teoria ou método jurídico é afastado de plano. No mesmo sentido, são recusados os métodos jurídicos que se afirmam como absolutos, com a fundamentação de que qualquer julgador, ao utilizá-los, chegará à mesma decisão.

\subsection{A possibilidade de uma jurisdição constitucional fundamentada na ética da tolerância.}

Há uma discussão sobre o conceito de pós-modernidade e autores como Habermas dirão que não estamos na pós-modernidade, mas sim na alta modernidade. Para estes, a atual sociedade ainda não conseguiu vencer a modernidade porque apenas recentemente atenta para mazelas sociais, como a escravidão e a segregação de mulheres. 


\begin{abstract}
Conjugando o pensamento de Habermas e concebendo as sociedades modernas num estado de alta ou radicalizada modernidade, que apresenta como característica dominante um elevado grau de reflexividade, Giddens (1997) prefere a expressão modernidade reflexiva ou tardia, pois acredita que a modernização reflexiva possibilita o entendimento e a criação de interpretações que possam responder às descontinuidades da modernidade, geradas a partir das mudanças da vida moderna. $\mathrm{O}$ autor entende que esse processo favorece o potencial destrutivo envolvido na relação dos homens com a natureza e dos homens entre eles mesmos, aumentando o nível de perigo vivenciado na vida coletiva. (LUVIZOTTO, 2013, p. 250)
\end{abstract}

Esses autores também defendem que a grande proposta do racionalismo e da metafísica clássica, com o surgimento do iluminismo, foi racionalizar os mitos da Idade Média por meio da aplicação do método científico. Todavia, ao buscar a racionalidade foi criado o maior de todos os mitos, o de que a crença no método científico fosse capaz de revelar uma verdade atemporal, definitiva e inquestionável.

O agir puramente lógico ou metodológico dos juristas já foi descaracterizado nos tópicos anteriores. A ética da tolerância procura revelar as premissas em que o julgador se apoia para emitir sua decisão, assim como admitir que outras premissas também são legítimas como meios de interpretação.

Ao perceber que toda verdade é datada e precária, por ser fruto de um paradigma de precompreensões compartilhadas em um dado momento histórico, e que serão superadas com o passar do tempo, é que se produz uma nova forma de encarar os objetos que se pretendem conhecer, dando a eles um novo sentido.

A hermenêutica não pode ser o método que tem a pretensão de revelar aquele que seria o sentido próprio da norma ou a verdade acerca de qualquer investigação. O papel da ética da tolerância é afirmar que a precompreensão é constitutiva da compreensão do conhecimento científico. Então, o papel da hermenêutica seria desvelar as precompreensões e analisar quais são legítimas e quais são ilegítimas. A hermenêutica atual reabilita o conceito de preconceito ao dizer que ele é necessário, então, cabe à ciência discutir os preconceitos no sentido de pressuposição ou preconcepção. O importante é revelar as precompreensões por trás de qualquer afirmação ou decisão jurídica para verificar se são válidas ou não, independentemente de serem fruto de uma metafísica clássica, moderna ou pós-metafísica. 


\section{REFERÊNCIAS BIBLIOGRÁFICAS}

ADEODATO, João Maurício A retórica constitucional: sobre tolerância, direitos humanos e outros fundamentos éticos do direito positivo. São Paulo: Saraiva, 2010.

Uma teoria retórica da norma jurídica e do direito subjetivo. São Paulo: Noeses, 2011.

ARISTOTELES. Da Interpretação. Tradução: José Veríssimo Teixeira da Mata; São Paulo: Editora Unesp, 2013.

Retórica. Trad. Edson Bini. São Paulo: Edipro, 2013.

BALLWEG, Ottmar. Analytical rhetoric, semiotic and law. In: KEVELSON, Roberta. Law and semiotics. v. 1. New York: Plenum Press, p. 25-33, 1987.

Retórica Analítica e Direito. In: ADEODATO, João Mauricio; BITTAR, Eduardo C.B (Org.). Filosofia e teoria geral do direito: estudos em homenagem a Tércio Sampaio Ferraz Junior por seu septuagésimo aniversário. São Paulo: Quartier Latin, 2011.

CARVALHO NETTO, Menelick de. Requisitos pragmáticos da interpretação jurídica sob o paradigma do Estado Democrático de Direito. Revista Brasileira de Direito Comparado. Belo Horizonte, v. 3, p. 473-486, 2001.

A hermenêutica constitucional sob o paradigma do Estado Democrático de Direito. Jurisdição e hermenêutica constitucional, Mandamentos, Belo Horizonte, 2004.

DA SILVA, Virgílio Afonso O proporcional e o razoável. São Paulo: Revista dos Tribunais, v. 798, pp. 29-30, 2002.

DESCARTES, René. Discurso do Método. Rio de Janeiro: Nova Fronteira, 2011.

FREIRE, Paulo. Das qualidades indispensáveis ao melhor desempenho de professoras e professores progressistas. In: FREIRE, Paulo. Professora sim, tia não - cartas a quem ousar ensina. São Paulo: Olhos d'agua, 1993.

GADAMER, Hans-Georg. Verdade e Método: traços fundamentais de uma hermenêutica filosófica. Tradução Flávio Paulo Meurer. 2.ed. Petrópolis: Editora Vozes,1998.

GERMANO, Marcelo Gomes. Uma nova ciência para um novo senso comum Campina Grande: EDUEPB, 2011.

KANT, Immanuel. Crítica da razão pura. Os pensadores. vol. I. São Paulo: Nova Cultural, 1987.

LARENZ, Karl. Metodologia da ciência do direito. Trad. José Lamego. 3 ed. Lisboa: Fundação Calouste Gulbenkian, 1997.

LUHMANN, Niklas. Sistemas sociales: lineamientos para una teoría general. Trad. Silvia Peppe e Brunhilde Erker; Coord. Javier Torres Narrefete. Barcelona: Anthropos, 1998. 
LUVIZOTTO, Caroline Kraus A racionalização das tradições na modernidade: o diálogo entre Anthony Giddens e Jürgen Habermas. Trans/Form/Ação, Marília, v. 36, n. spe, p. 245-258, 2013.

MULLER, Friedrich. Métodos de Trabalho do Direito Constitucional, $3^{\mathrm{a}}$ ed, 2005.

PLATÃO. A república. Trad. Maria Helena da Rocha Pereira. 8 ed. Lisboa: Fundação Calouste Gulbenkian, 1996.

SANTOS, Boaventura de Souzsa. Introdução a uma ciência pós-moderna. Rio de Janeiro, Graal, 2003.

SCHLIEFFEN, Katharina von. Rhetorische Analyse des Rechts: Risiken, Gewinn und neue Einsichten, in: SOUDRY, Rouven (Hrsg.). Rhetorik - Eine interdisziplinäre Einführung in die rhetorische Praxis. Heidelberg: C. F. Muller Verlag, p. 42-64, 2006.

SOBOTA, Katharina. Rhetorisches Seismogramm - Eine neue Methode in den Rechtswissenschaften. Juristen Zeitung. vol. 47, nº 5, p. 231-237, 1992.

STRECK, Lênio Luiz. Jurisdição constitucional e hermenêutica: perspectivas e possibilidades de concretização dos direitos fundamentais-sociais no Brasil. Novos estudos jurídicos, v. 8, n. 2, p. 250-302. Rio de Janeiro: Renovar, 2008.

Verdade e consenso. Constituição, Hermenêutica e Teorias Discursivas. Da Possibilidade à necessidade de respostas em Direito. 3.ed. Rio de Janeiro: Lumen Juris, 2009.

Advogado. 2010.

O que é isto - decido conforme minha consciência? Porto Alegre: Livraria do

As recepções teóricas inadequadas em terrae brasilis. In: Revista de Direitos Fundamentais e Democracia, Curitiba, v. 10, n. 10, p. 2-37, jul./dez, 2011.

VIEHWEG, Theodor. Tópica e jurisprudência. Brasília: Departamento de Imprensa Nacional, 1979.

XAVIER, Dennys Garcia. Para uma metafísica platônica à luz da "tradição indireta". Revista Hypnos, n. 15, p. 117-128, 2015.

WITTGENSTEIN, Ludwig. Investigações filosóficas. Tradução de Marcos G. Montagnoli. 2.ed. Petrópolis: Vozes, 1996.

Data de Submissão: 23/05/2020

Data de Aceite: 05/09/2020 